\title{
Tümüyle Elektrikli Binek Tipli Bir Araçta Yuvarlanma Direnci Değişiminin İvmelenme Performansı ve Transmisyon Kayıplarına Etkisi Üzerine Bir Çalışma
}

\author{
M. Akif KUNT \\ Kütahya Dumlupınar Üniversitesi, Tavşanlı M.Y.O, Motorlu araçlar ve Ulaştırma Teknolojileri Bölümü, Tavşanlı- \\ Kütahya, TÜRKIYE \\ mehmetakif.kunt@dpu.edu.tr
}

Received/Geliş: 24.02 .2020

Accepted/Kabul: 20.04.2020

Öz: Elektrikli araçların günümüzde halen istenilen düzeyde kullanılmamasının en önemli sebebi sınırlı menzilleridir. Elektrikli araçların menziline etki eden en önemli faktörlerden birisi yuvarlanma direnci etkisidir. Lastik tasarımına ve çevresel koşullara bağlı olarak değiş̧ebilen yuvarlanma direnç kuvveti değişimi fren ve batarya performansıyla birlikte menzili de etkilemektedir. Bu çalışmada binek tipli tümüyle elektrikli bir araç için ADVISOR taşıt simülasyon programı kullanılarak iki farklı yuvarlanma direncinde elektrikli aracın ivmelenme ve transmisyon kayıpları incelenmiştir. Sürüş çevrimine göre ortalama yuvarlanma direnç kuvvetleri arasında 2.1 kat fark meydana gelmiştir. Düşük yuvarlanma dirençli lastiklerin hızlanma süresi $0-96.6 \mathrm{~km} / \mathrm{h}$ hızlar arasında 0.4 saniye, $64.4-96.6 \mathrm{~km} / \mathrm{h}$ hızlar arasında 0.2 saniye, $0-137 \mathrm{~km} / \mathrm{h}$ hızlar arasında ise 0.5 saniye azalmıştır. Ayrıca frenleme enerjisi düşük yuvarlanma dirençli lastiklerde $\% 7.3$ daha fazla meydana gelmiş̧ir.

Anahtar kelimeler: Yuvarlanma direnci, transmisyon kayıpları, sürüş çevrimi, ivmelenme, rejenerasyon

\section{A Study on the Effect of Rolling Resistance Change on Acceleration Performance and Transmission Losses in An All-Electric Passenger Type Vehicle}

\begin{abstract}
The most important reason of electric vehicles are still not being used at the desired level today is their limited range. One of the most important factors affecting the range of electric vehicles is the rolling resistance effect. The change in rolling resistance force, which can vary depending on tire design and environmental conditions, affects the range along with brake and battery performance. In this study, rolling resistance force change, SOC status and battery recovery has been examined in 2 different rolling resistance using the ADVISOR vehicle simulation program for an all-electric vehicle of passenger type There has done a 2.1 times difference between the average rolling resistance forces according to the driving cycle. With low rolling resistance tire acceleration time on has reduced by 0.4 seconds between speeds of $0-96.6 \mathrm{~km} / \mathrm{h}, 0.2$ seconds between speeds of $64.4-96.6 \mathrm{~km} / \mathrm{h}$, and 0.5 seconds between speeds of $0-137 \mathrm{~km} / \mathrm{h}$. In addition, braking energy has been $7.3 \%$ higher at low rolling resistance tire.
\end{abstract}

Keywords: Rolling resistance, transmission losses, driving cycle, acceleration, regeneration

\section{Giriş}

Otomobil üretim teknolojilerinin gelişmesi ile üretilen otomobillerin sayısı da artmaktadır. Bu durum otomobillerden beklentileri artırarak enerji gereksiniminin daha fazla artmasına neden olmuştur. Dünya

Bu makaleye atıf yapmak için

Kunt, M.A., "Tümüyle Elektrikli Binek Tipli Bir Araçta Yuvarlanma Direnci Değișiminin İvmelenme Performansı ve Transmisyon Kayıplarına Etkisi Üzerine Bir Calıșma" El-Cezerî Fen ve Mühendislik Dergisi 2020, 7(2); 743-752. 
üzerindeki enerji rezervlerinin daha verimli kullanılması ve taşıt kaynaklı kirlenmenin azaltılabilmesi için elektrikli araçlar önemli bir alternatiftir. Çevre duyarlılı̆̆ araçlar son zamanlardaki en uygun taşıtlardır [1]. Elektrikli araçların (EA) yaygınlaşmasını etkileyen en önemli faktörler; uzun şarj süresi ve araçların kısa menzil mesafeleridir [2]. EA'ların menzillerinin artırılmasında en önemli faktörler taşıt ön izdüşüm alanı, batarya enerji yoğunluğu ve yuvarlanma direnç katsayısıdır [3]. Elektrikli araçların sürüş sırasındaki kayıplarının azaltılması enerji verimliliğini arttıran yöntemlerden birisidir. Hareket dirençleri taşıt enerji kayıpları üzerinde çok büyük bir yer tutmaktadır. Hareket dirençlerimin en önemlisi yuvarlanma direnç kuvvetidir [4]. Yuvarlanma direnci ile taşıtın enerji tüketimi arasında doğrudan bir bağlantı vardır [5]. Yuvarlanma direnci sürüş halindeki bir taşıtın oluşturduğu enerjinin \%25'ini harcamaktadır. Birçok değişkene bağlı olan yuvarlanma direnci katsayısının artması tahrik sırasında aşılması gereken dirençleri arttırmaktadır [6]. Bu durum elektrikli araçların menzillerinin artırılması konusunda yuvarlanma direncini oldukça önemli bir konuma getirmektedir. Özellikle düşük taşıt hızlarında yuvarlanma direnç kuvveti enerji kayıpları açısından büyük önem kazanmaktadır [7]. Yuvarlanma direncinin taşıttaki diğer enerji kayıpları arasındaki durumu Şekil 1' de gösterilmiştir.

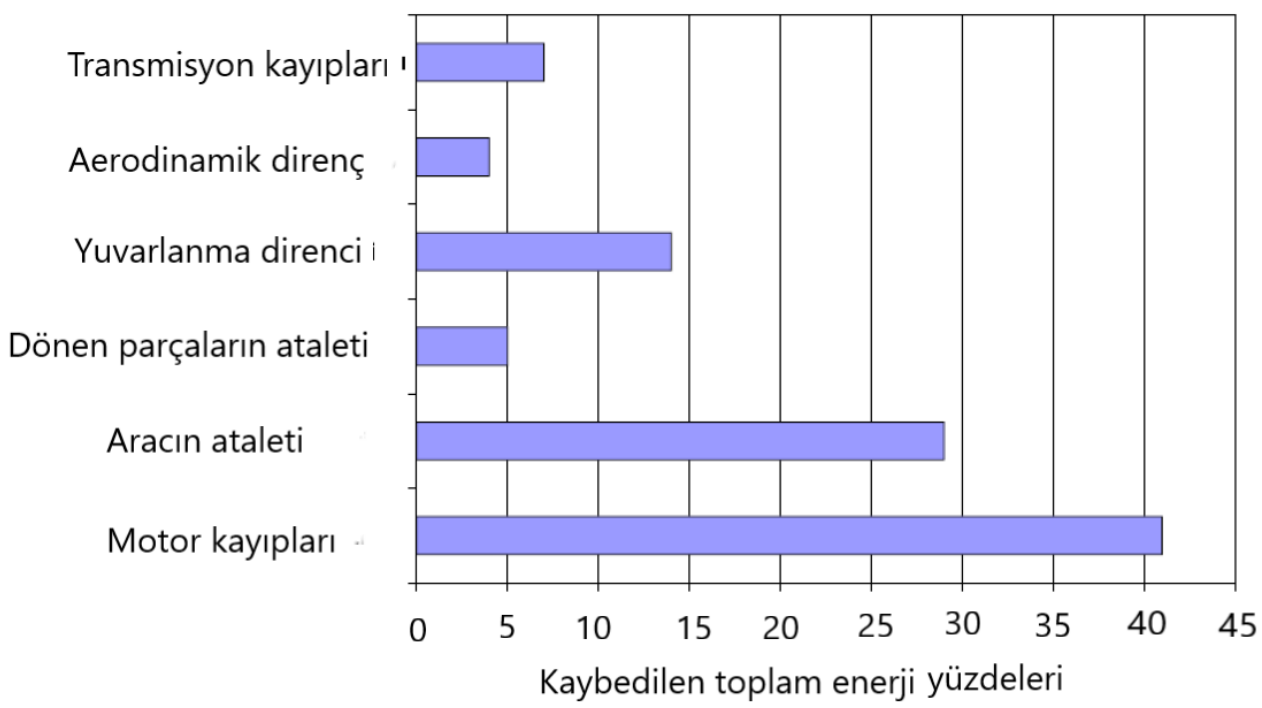

Şekil 1. Taşıt enerji kayıplarının yüzde gösterimi [8]

Günümüzde otomobil lastiklerinin yuvarlanma direnç katsayıları genel olarak 0.007-0.014 arasında değişmektedir [9]. Yuvarlanma direncine etki eden temel faktörler sürüş koşulları, taşıt hızı, lastik şişirme basıncı ve lastiğe etki eden düşey yüktür. Bu faktörler frenleme, tahrik ve tutunma durumları dikkate alınarak optimum bir değerde tutulursa elektrikli otomobillerde enerji tasarrufu sağlanarak menzil artırılabilir. Lastik yuvarlanma direncinin standart ölçüm teknikleri Amerikan Otomobil Mühendisler Odasının SAE J1269 ve SAE J1270 standartlarında tanımlanmıştır. SAE J1269 standardı, laboratuvar ortamında karayolunda kullanılan binek otomobil, hafif kamyon ve otobüs lastiklerinin yuvarlanma direncinin belirlenmesi amacıyla hazırlanmıştır. SAE J2452 standartlarına göre de yuvarlanma direnç kuvveti hesaplanabilmektedir.

\section{Elektrikli Aracın Modellenmesi}

Literatürde yuvarlanma direncinin taşıt performansına etkisini gösteren ve elektrikli araçların modellenmesine yönelik yakın geçmişte pek çok çalışma bulunmaktadır [10-19]. Elektrikli aracın modellenmesi amaciyla ADVISOR (Advanced Vehicle Simulator) programı kullanılmıştır. Gerçek sürüş şartlarında çevresel kararlılığın (yol eğimi, yuvarlanma direnç katsayısı, çevre sıcaklığı vb) sağlanmasında karşılaşılan zorluklar sebebiyle simülasyon yoluyla analiz yapılmasına karar verilmiştir. $\mathrm{Bu}$ program yeni araçların gelişimine hızlandırmak için $\mathrm{ABD}$ hükümeti tarafından kurulan Ulusal 
Yenilenebilir Enerji Laboratuvarı' nın (NREL-National Renewable Energy Laboratory) oluşturduğu bir simülasyon programıdır. Bu programda kullanıcı modellemeyi iki adımda gerçekleştirmektedir [20]. Program otomobil üreticileri ve üniversitelerin katılımıyla güncellenmiş ve yeni özellikler eklenmiştir [21]. ADVISOR, programın kullanımını kolaylaştırmak amacıyla, grafiksel kullanıcı ara yüzünden de yararlanmaktadır. Araç tipi ve bileşenlerinin seçiminde kullanılan tanımlama ekranı Şekil 2'de gösterilmiştir.
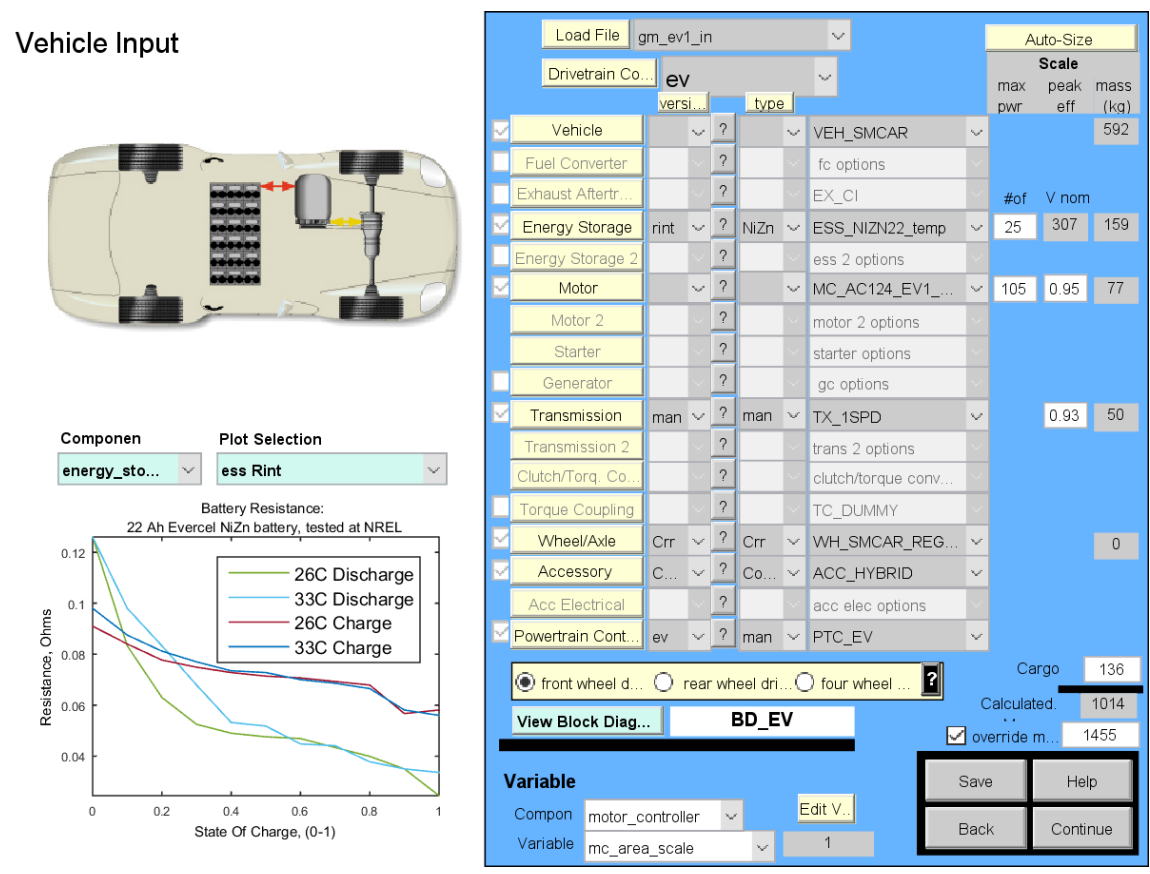

Şekil 2. ADVISOR giriş ekranı

Sürüş çevrimi olarak maksimum hızı $50 \mathrm{~km} / \mathrm{h}$ olan ve düşük hızlarda kullanılan NYCC (New York City Cycle) sürüş çevrimi seçilmiştir. Sürüş çevrimine ait özellikler Tablo 1'de gösterilmiştir.

Tablo1. Sürüș çevriminin özellikleri.

\begin{tabular}{lcc}
\hline Veriler & Değerler & Birimler \\
\hline Süre & 598 & $\mathrm{~s}$ \\
Mesafe & 1.9 & $\mathrm{~km}$ \\
Maksimum hız & 44.58 & $\mathrm{~km} / \mathrm{h}$ \\
Ortalama hız & 11.41 & $\mathrm{~km} / \mathrm{h}$ \\
Maksimum ivme & 2.68 & $\mathrm{~m} / \mathrm{s}^{2}$ \\
Maksimum yavaşlama ivmesi & -2.64 & $\mathrm{~m} / \mathrm{s}^{2}$ \\
Relanti süresi & 210 & $\mathrm{~s}$ \\
Duraklama sayısi & 18 & \\
\hline
\end{tabular}

\subsection{Aracın Hareketine Etki Eden Kuvvetler}

Aracın hareketine etki eden temel kuvvetler çevresel faktörlerinde etkili olduğu direnç kuvvetleri ve direnç kuvvetlerini karşılamak üzere motor tarafından üretilen gücün tekerleklere kadar iletilmesini sağlayan tahrik (çekiş) kuvvetidir. Direnç kuvvetleri denklem 1'de gösterilen lastiklerdeki yuvarlanma direnci $\left(F_{y}\right)$, aerodinamik (hava) sürtünme $\left(F_{h}\right)$, aracın aşması gereken atalet direnci $\left(F_{a}\right)$ ve eğim direnci $\left(F_{e}\right)$ 'dir. Aracın tahrik edilebilmesi için tüm bu dirençlerin aşılması gerekmektedir. 


$$
\begin{gathered}
F_{t}=F_{y}+F_{h}+F_{a}+F_{e} \\
F_{y}=f_{\text {ro }} G
\end{gathered}
$$

(2) no' lu denklemde $\left(f_{\text {ro }}\right)$ yuvarlanma direnç katsayısını, $(\mathrm{G})$ taşıt ağırlı̆̆ını ifade etmektedir. Yuvarlanma direnci taşıtın hızlanma performansına önemli ölçüde etki etmektedir.

\subsection{Yuvarlanma direnç katsayısı}

Yuvarlanma direnci SAE J2452 standartlarına göre hesaplanmıştır. SAE J2452 lastik yuvarlanma direncinin hesaplanması için hazırlanmış bir standarttır. Daha önce kullanılan SAE J1269 standardı lastiğin çalışma koşullarında kararlı durumda olduğunu kabul ederken SAE J2452 standardı farklı taşıt yükü, lastik basıncı ve hızlarının yuvarlanma direncine etkisini belirleyebilmektedir. Bu standarda göre yuvarlanma direnç kuvveti:

$$
F_{r}=P^{a} Z^{\beta}\left(a+b V+c V^{2}\right)
$$

(3) no'lu bağıntıda (P) lastik basıncını, (Z) lastiğe düşeyde tesir eden yükü, (V) taşıt hızını, (a, b, c) model için hesaplama katsayılarını göstermektedir. (a), (b) ve (c) katsayılarının değeri sırasıyla yuvarlanma direncinin değerine göre Tablo’2 de verilmiştir.

Tablo 2. SAE J2452 test standartlarına göre yuvarlanma direnç kuvveti hesaplama katsayıları.

\begin{tabular}{llll}
\hline & \multicolumn{1}{c}{ a } & \multicolumn{1}{c}{ b } & \multicolumn{1}{c}{ c } \\
\hline Yuvarlanma direnci (düşük) & 0.0682 & $2.32 * 10^{(-4)}$ & $1.2 * 10^{(-6)}$ \\
Yuvarlanma direnci (yüksek) & 0.159 & $3.44 * 10^{(-4)}$ & $1.25 * 10^{(-6)}$ \\
\hline
\end{tabular}

\section{Materyal ve Metot}

Modellemesi yapılan elektrikli aracın parametreleri Tablo 3'te verilmiştir. ADVISOR taşıt simülasyon programı kullanılarak sonuç grafikleri oluşturulmuştur. SAE J2452 standartlarına göre 2 farklı yuvarlanma direnç kuvveti elde edilmiştir.

Tablo 3. Taşıta ait model parametreleri.

\begin{tabular}{lll}
\hline Veriler & Değerler & Birimler \\
\hline Taşıt kütlesi & 1465 & $\mathrm{~kg}$ \\
Lastik yarıçapı & 0.3 & $\mathrm{~m}$ \\
Yerçekimi ivmesi & 9.81 & $\mathrm{~m} / \mathrm{s}^{2}$ \\
Yoğunluk (Hava) & 1.204 & $\mathrm{~kg} / \mathrm{m}^{3}$ \\
Rejeneratif frenleme oranı & 30 & $\%$ \\
İnvertör verimi & 95 & $\%$ \\
Konvertör verimi & 95 & $\%$ \\
Batarya verimi & 95 & $\%$ \\
Diferansiyel redüksiyon oranı & 10 & \\
Elektrik motor verimi & 95 & $\%$ \\
Lastik ölçüleri & $205 / 60 \mathrm{R} 15$ & \\
Batarya modül sayısı & 26 & \\
Batarya kapasite & 80 & $\mathrm{Ah}$ \\
\hline
\end{tabular}


Elektrikli taşıtların şehir içi sürüşlerinde daha verimli olması sebebiyle dur-kalk sayısı fazla olan NYCC (New York City Cycle) sürüş çevrimi seçilmiştir. NYCC sürüş çevrimine göre 1 sürüş çevriminde meydana gelen hılanma performansları benzetilmiştir. Aracın durgun hava içerisinde hareket ettiği ve yol eğiminin olmadığı kabul edilmiştir. Lastik basıncı ve lastiğe düşeyde tesir eden yük sürüş çevrimi boyunca değişmemektedir.

\section{Sonuçlar ve Tartışma}

Şekil 3'te sürüş çevrimine göre zaman bağlı mesafe değişimi görülmektedir. 18 adet duraklama sayısına sahip olan sürüş çevrimi 598 saniye sürmektedir. Çevrim tamamlandığında $1.9 \mathrm{~km}$ yol edilmiş olup rölanti süresi toplam 210 saniyedir.

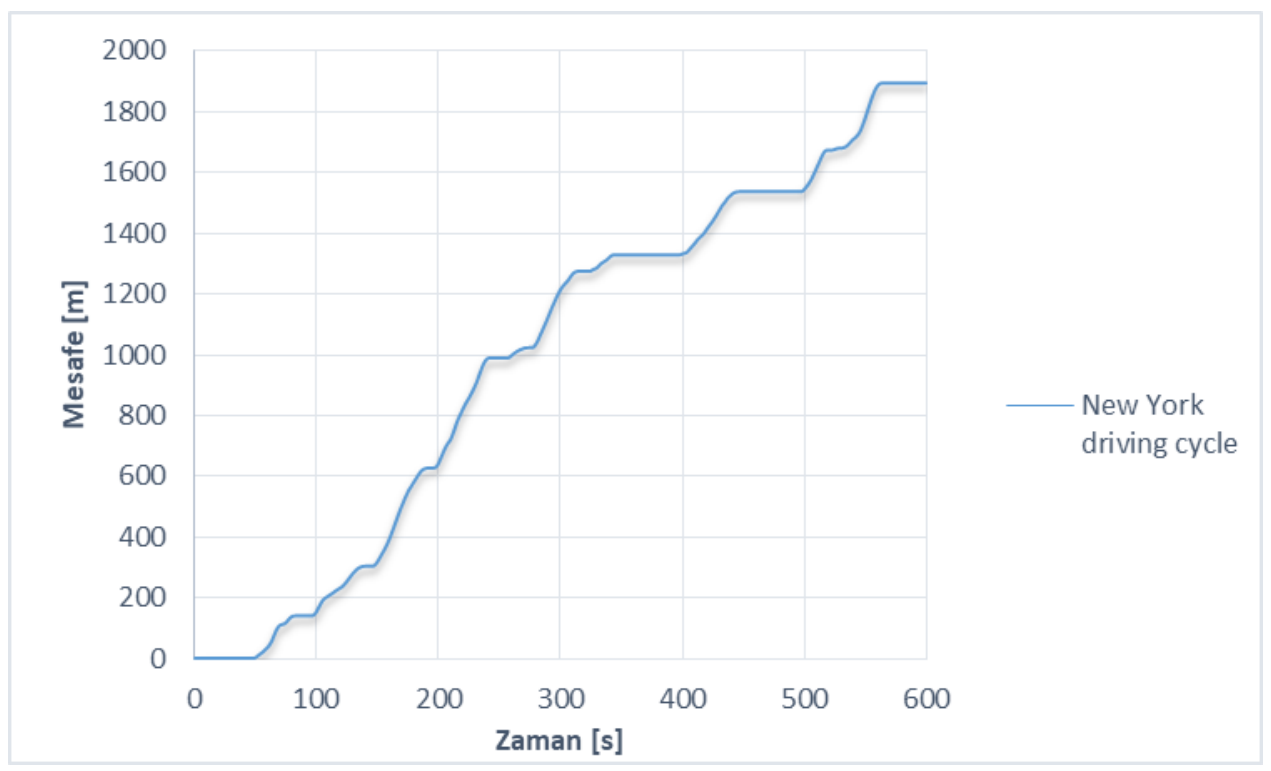

Şekil 3. NYCC çevrimine göre zamana bağlı mesafe değişimi

Şekil 4'te zaman bağlı taşıt hızı değişimi gösterilmiştir. Seçilen sürüş çevrimi dur-kalk sayısı fazla olan bir çevrimdir. Bu nedenle hızlanma ivmesi $2.68 \mathrm{~m} / \mathrm{s}^{2}$, yavaşlama ivmesi ise $-2.64 \mathrm{~m} / \mathrm{s}^{2}$ olarak gerçekleşmiştir. Sürüşs sırasında maksimum hız $44.58 \mathrm{~km} / \mathrm{h}$ olarak gerçekleşmektedir. Çevrimin ortalama hızı $11.41 \mathrm{~km} / \mathrm{h}$ 'dir.

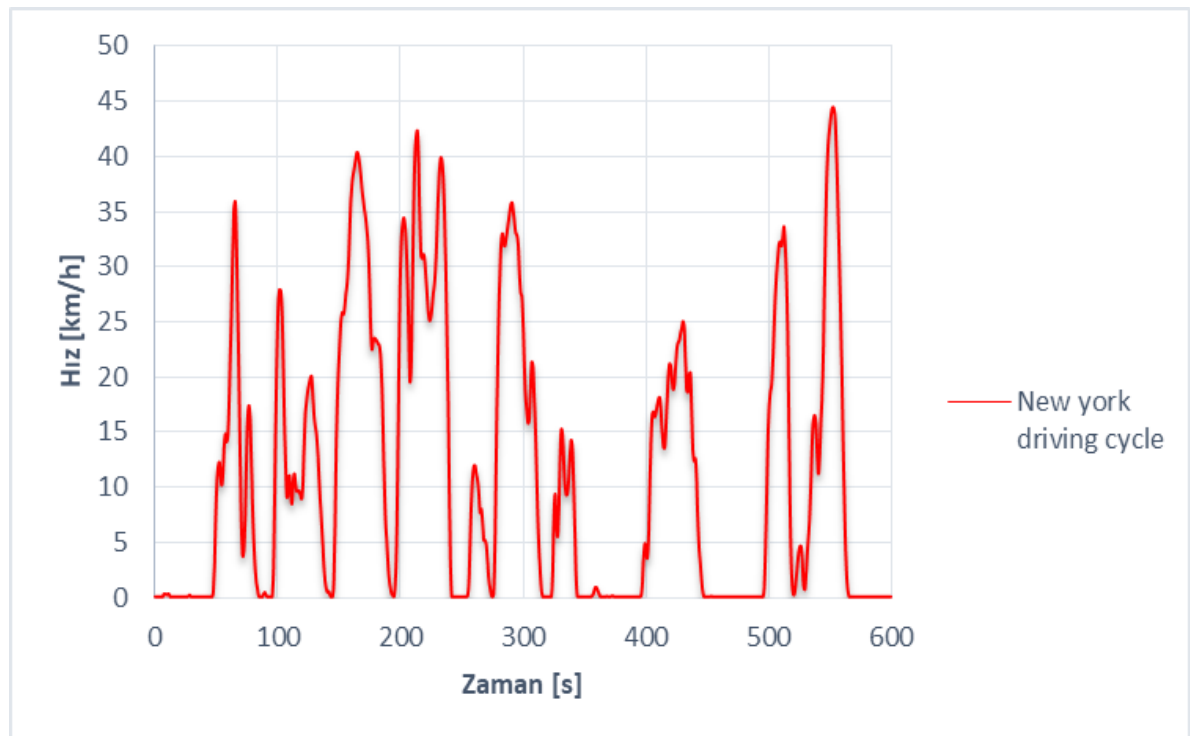

Şekil 4. NYCC çevrimine göre zamana bağlı taşıt hızı değişimi 
Şekil 5'te zaman bağlı yuvarlanma direnç kuvveti değişimi karşılaştırmalı olarak verilmiştir. Duraklama süreleri de dikkate alınarak 1 çevrimde yuvarlanma direnci düşük lastiklerde ortalama 44.6 N, yuvarlanma direnci yüksek lastiklerde ise ortalama $93.76 \mathrm{~N}$ yuvarlanma direnç kuvveti meydana gelmiştir. Yuvarlanma direnç kuvvetleri arasında 2.1 kat fark meydana gelmektedir. 2 lastiğin lastik basınçları ve lastiğe tesir eden düşey yük değerleri aynıdır. Rijit zemin üzerinde yapılan bu simülasyon çalışmasında yapılan kabullerin olmadığı gerçek sürüş şartlarında yuvarlanma direncinin taşıta etkisi daha fazla olacaktır.

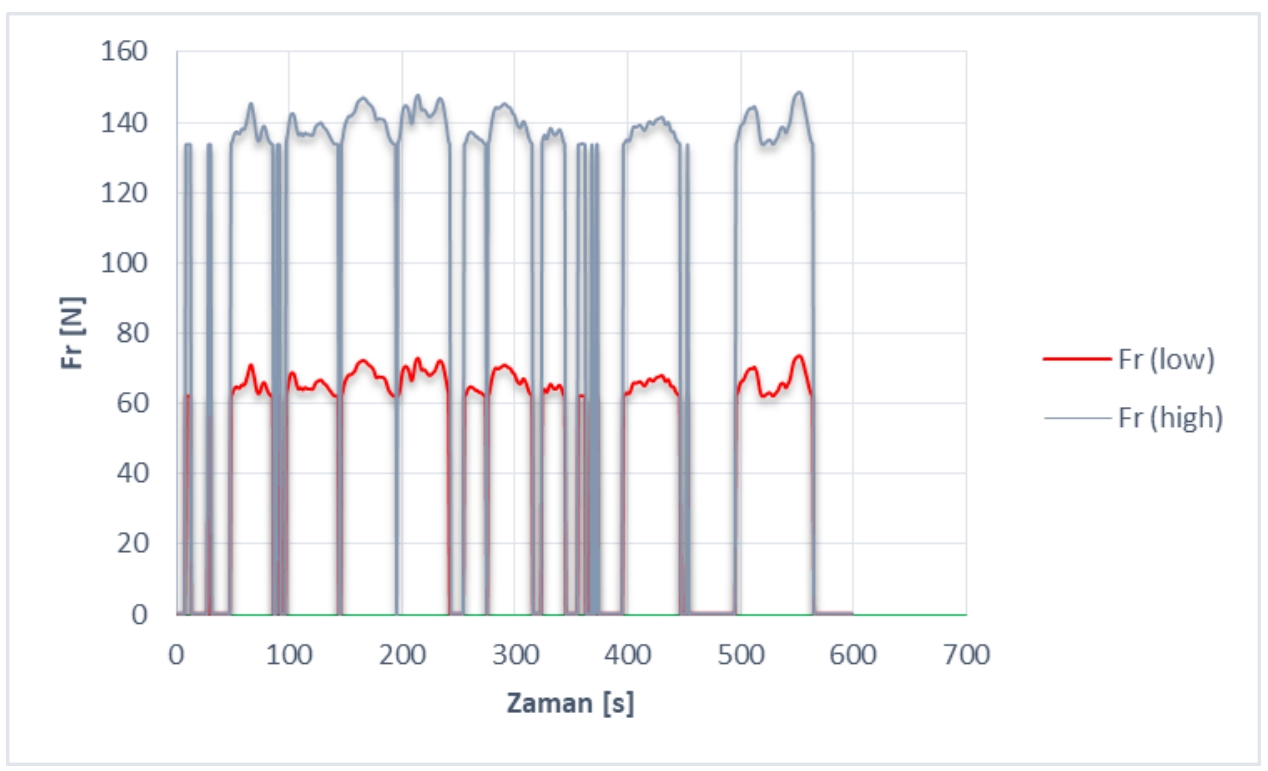

Şekil 5. NYCC çevrimine göre zamana yuvarlanma direnç kuvvetinin değişimi

Tablo 4'te simülasyon sonucu elde edilen bazı sonuç çıktıları gösterilmiştir. 1 sürüş çevrimi için düșük yuvarlanma dirençli lasti5 \% 6.25 yakıt ekonomisi sağlamıștır. 0-96.6 km/h hızlar arasında hızlanma süresinde düşük yuvarlanma dirençli lastik kullanılması durumunda 0.4 saniye azalma meydana gelmiştir.

Tablo 4. Simülasyon sonucu elde edilen sonuç çıtıları

\begin{tabular}{lccc}
\hline \multicolumn{1}{c}{ Parametre } & $\begin{array}{c}\text { Yuvarlanma } \\
\text { direnci (Düşük) }\end{array}$ & $\begin{array}{c}\text { Yuvarlanma } \\
\text { direnci (Yüksek) }\end{array}$ & Birimler \\
\hline Eşdeğer benzin & 3 & 3.2 & 1 \\
Mesafe & 1.9 & 1.9 & $\mathrm{~km}$ \\
$0-96.6$ & 9.2 & 9.6 & $\mathrm{~km} / \mathrm{h}$ \\
$64.4-96.6$ & 3.8 & 4 & $\mathrm{~km} / \mathrm{h}$ \\
$0-137$ & 18.2 & 18.7 & $\mathrm{~km} / \mathrm{h}$ \\
Frenleme (Rejenerasyonlu) & 395 & 366 & $\mathrm{~kJ}$ \\
Tekerlek/Aks (Rejenerasyonlu) & 4 & 3 & $\mathrm{~kJ}$ \\
Vites kutusu (Rejenerasyonlu) & 57 & 53 & $\mathrm{~kJ}$ \\
Motor/Kontrolör (Rejenerasyonlu) & 87 & 80 & $\mathrm{~kJ}$ \\
Yuvarlanma direnci & 130 & 269 & $\mathrm{~kJ}$ \\
Aerodinamik direnci & 26 & 26 & $\mathrm{~kJ}$ \\
Tekerlek/Aks (Power mode) & 64 & 67 & $\mathrm{~kJ}$ \\
Vites kutusu (Power mode) & 153 & 166 & $\mathrm{~kJ}$ \\
Motor/Kontrolör & 379 & 390 & $\mathrm{~kJ}$ \\
\hline
\end{tabular}


64.4-96.6 km/h hızlar arasında hızlanma süresinde düşük yuvarlanma dirençli lastik kullanılması durumunda 0.2 saniye azalma meydana gelmiştir. $0-137 \mathrm{~km} / \mathrm{h}$ hızlar arasında hızlanma süresinde düşük yuvarlanma dirençli lastik kullanılması durumunda 0.5 saniye azalma meydana gelmiştir. Advisor programı bu hızlanma performansındaki değerlendirmeleri ileri yönlü iterasyon yaparak hazırlamaktadır. Frenleme sırasında gereken enerjinin yüksek yuvarlanma dirençli lastiklerde daha fazla absorbe edilmesi sebebiyle frenleme enerjisi düşük yuvarlanma dirençli lastiklerde $\% 7.3$ daha fazla meydana gelmiştir. Ayrıca 1 sürüş çevrimi için tahrik durumunda aerodinamik direnç dişında diğer aktarma organları kayıpları yüksek yuvarlanma dirençli lastiklerde daha fazladır.

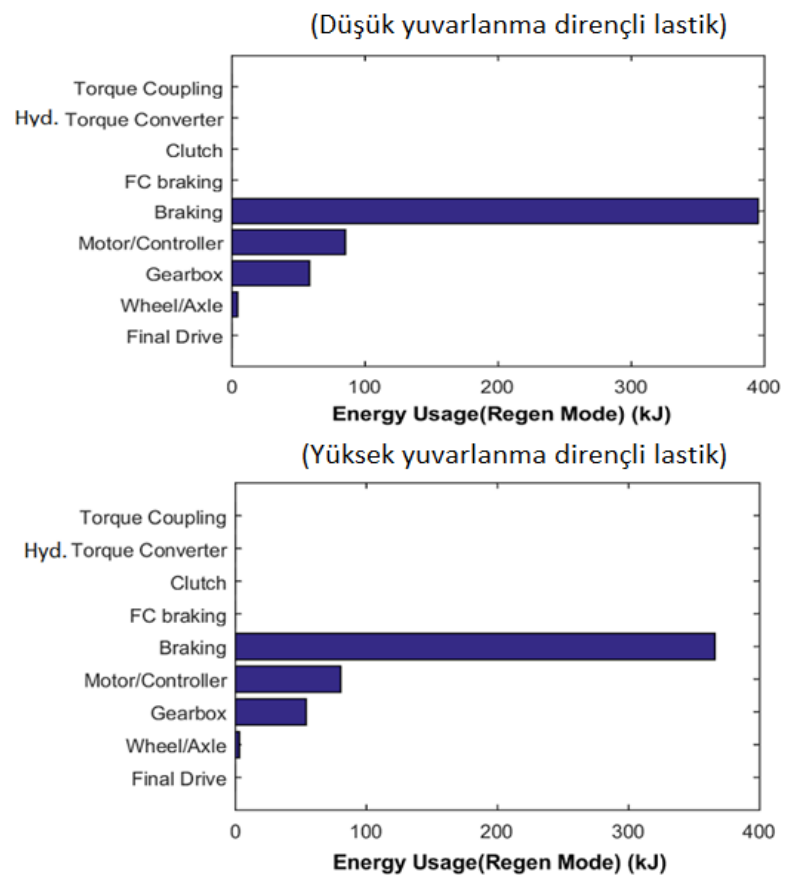

Şekil 6. Frenleme durumunda taşıt enerji kayıpları
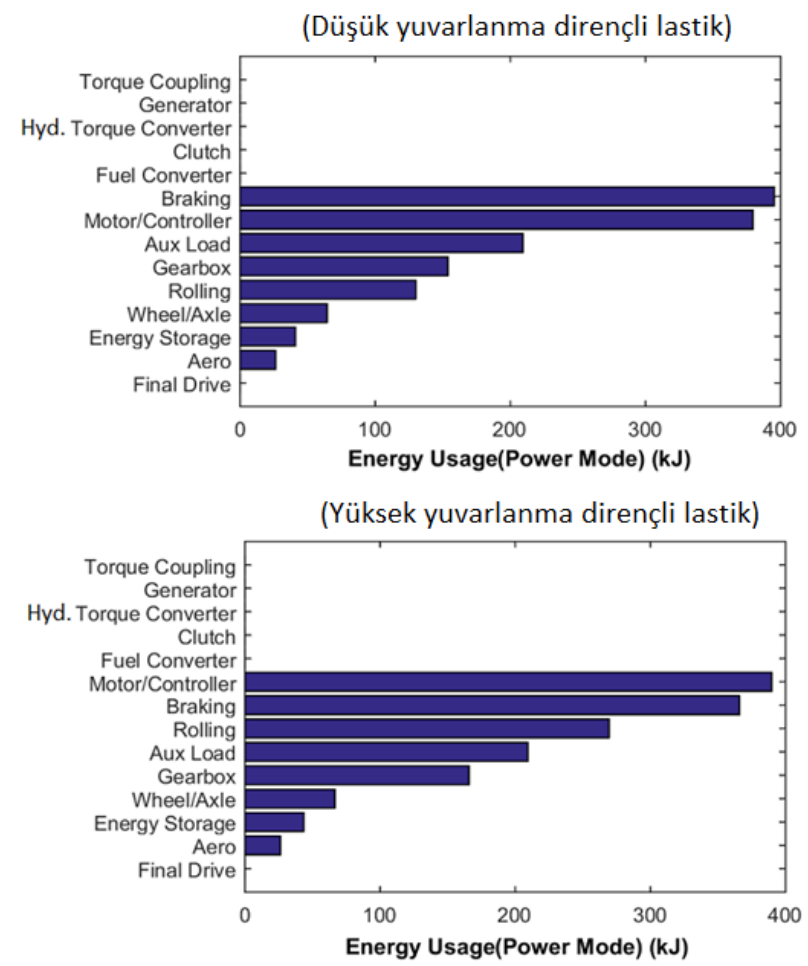

Şekil 7. Tahrik durumunda taşıt enerji kayıpları 
Şekil 6'da rejenerasyon sırasında yuvarlanma dirençlerine ait enerji kayıplarını göstermektedir. Rejenerasyonlu frenleme sırasında düşük yuvarlanma dirençli lastik daha fazla enerji tüketmiştir. Transmisyon ve motor kayıpları da bataryaların daha yoğun deşarj olmaları yüksek yuvarlanma dirençli lastiklere göre sebebiyle daha yüksektir. Tahrik sırasında ise yüksek yuvarlanma dirençli lastiğin enerji tüketimini fazla olması güç aktarma organlarındaki kayıpları artırmıştır.

Şekil 7'de tahrik sırasında yuvarlanma dirençlerine ait enerji kayıplarını göstermektedir. Tahrik sırasında düşük yuvarlanma dirençli lastik \% 4.4 daha düşük miktarda enerji tüketmiştir. Transmisyon ve motor kayıpları da yuvarlanma direncinin daha az oluşması sebebiyle yüksek yuvarlanma direncine sahip lastiklere göre daha düşüktür. Tahrik sırasında ise düşük yuvarlanma dirençli lastikte daha yüksek rejenerasyon kazanımı olması sebebiyle batarya şarj yoğunluğu artmış ve \% 8.4 daha fazla batarya kaybı meydana gelmiştir. Batarya enerji kaybının sebebi rejenerasyon işlemi sırasında bataryada meydana gelen şarj-deşarj yoğunluğunun fazla olmasıdır. Aerodinamik direnç kuvveti değişmemiştir.

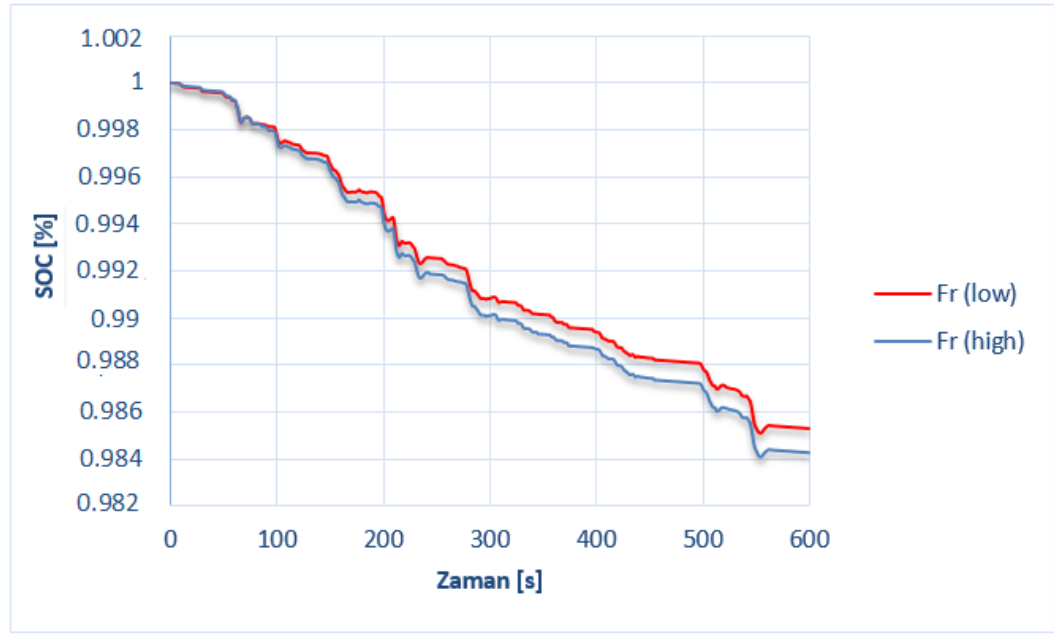

Şekil 8. Zamana bağlı SOC değişimi

Şekil 8' de 1 sürüş çevrimi için zamana bağlı SOC değişimi görülmektedir. Sürüş çevrimi boyunca her iki lastiğin SOC değişimi benzerlik göstermektedir.

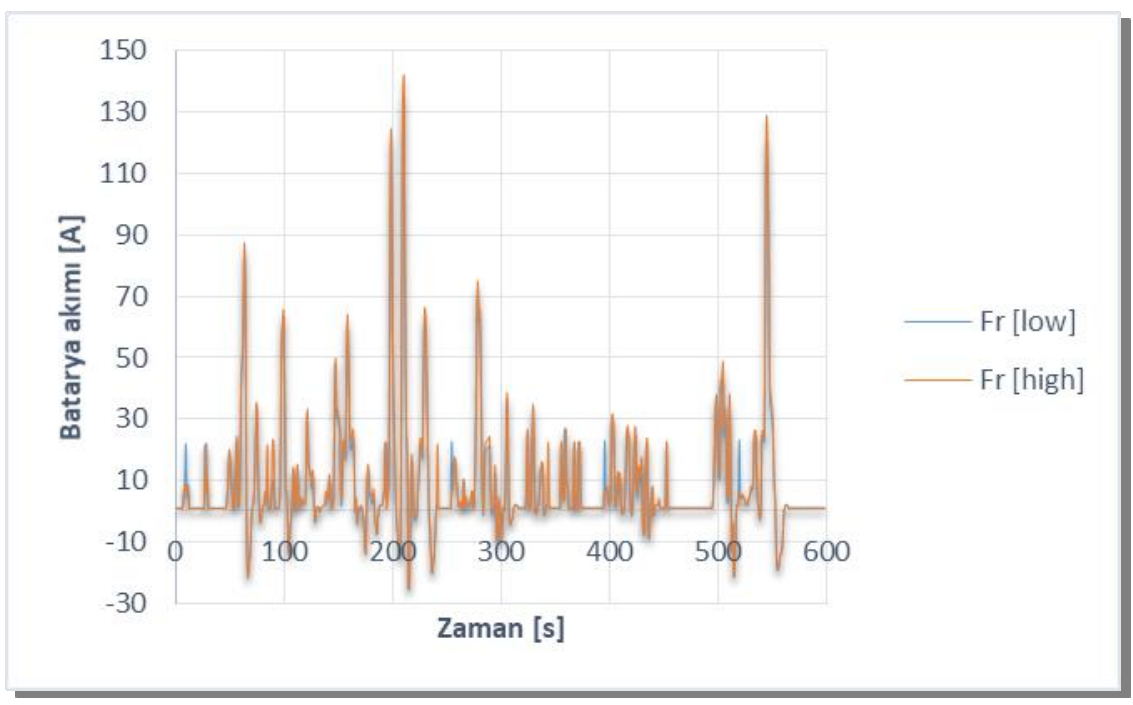

Şekil 9. Zamana bağlı batarya şarj akımı değişimi 
Tam dolu batarya kabulü yapıldığında 1 sürüş çevrimi sonunda yüksek yuvarlanma dirençli lastiğin SOC değeri \% 98.53, düşük yuvarlanma dirençli lastiğin SOC değeri ise \% 98.41 olarak gerçekleşmiştir. Sürüş çevriminde alınan yolun $1.9 \mathrm{~km}$ olduğu dikkate alındığında $100 \mathrm{~km}$ yol alınması durumunda düşük ve yüksek yuvarlanma dirençli lastik kullanımı arasında \% 6.32 değerinde bir SOC farkı meydana gelecektir.

Şekil 9'da batarya şarj akımı değişim grafiği görülmektedir. Sürüş çevrimi genelinde yüksek yuvarlanma dirençli lastik kullanımı durumunda bataryadan daha fazla akım çekilmiştir. Bu grafik SOC değişim grafiğini de doğrulamaktadır. Bununla birlikte 7-12 s., 395-398 s. ve 518-522 s. zaman aralıklarında düşük yuvarlanma dirençli lastik için daha yüksek batarya akımı çekilmiştir. İlgili zaman aralıklarında araç durgun durumdan hızlanmaktadır. İlk kalkış durumunda düşük yuvarlanma dirençli lastiğin daha zayıf bir tutunma gerçekleştirmesi sebebiyle daha yüksek batarya akımının çekilmiştir. Tüm seyir çevrimi değerlendirildiğinde ise yüksek yuvarlanma dirençli lastiğin ortalama batarya akım değeri 9.24 A, düşük yuvarlanma dirençli lastiğin ortalama batarya akım değeri 8.51 A olarak gerçekleşmiştir. Düşük yuvarlanma dirençli lastik kullanımı batarya akımını $\% 8$ azaltmaktadır.

\section{Sonuçlar}

Seçilen sürüş çevrimine göre yuvarlanma direnç kuvvetleri arasında 2.1 kat fark meydana gelmiştir. Yuvarlanma direnci düşük lastiğin 0-96.6 km/h hızlar arasında hızlanma süresinde 0.4 saniye, 64.4$96.6 \mathrm{~km} / \mathrm{h}$ hızlar arasında hızlanma süresinde 0.2 saniye, $0-137 \mathrm{~km} / \mathrm{h}$ hızlar arasında ise 0.5 saniye azalma meydana gelmiştir. Yüksek yuvarlanma dirençli lastiklerde frenleme sırasında gereken enerjinin daha fazla absorbe edilmesi sebebiyle frenleme enerjisi düşük yuvarlanma dirençli lastiklerde \% 7.3 daha fazla meydana gelmiştir. Yüksek yuvarlanma dirençli lastiklerde transmisyon ve motor kayıpları bataryaların daha yoğun deşarj olmaları göre sebebiyle daha yüksektir. Tahrik durumunda (Power mode) yüksek yuvarlanma direncine sahip lastiğin vites kutusu ve aks kayıları \%7 daha fazla meydana gelmiştir. Rejenerasyon durumunda ise düşük yuvarlanma direncine sahip lastiğin rejenerasyon kazanımının fazla olması sebebiyle vites kutusu ve aks kayıpları daha yüksektir. Rejenerasyon kazanımının yüksek olması sebebiyle düşük yuvarlanma direncine sahip lastiklerde batarya şarj yoğunluğu artmış ve \% 8.4 daha fazla batarya kaybı meydana gelmiştir. 100 km esas alındığında düşük yuvarlanma dirençli lastik kullanımının \% 6.32 daha yüksek SOC değeri elde edilmesini sağlamıştır. Batarya akımı incelendiğinde ise 1 sürüş çevriminde düşük yuvarlanma dirençli lastiğin ortalama batarya deşarj akımı $\% 8$ daha azdır.

\section{Teşekkür}

$\mathrm{Bu}$ çalışma 10-12 Ekim 2019 tarihleri arasında Gaziantep Üniversitesi'nde düzenlenen The International Conference of Materials and Engineering Technologies (TICMET'19) kongresinde sözlü bildiri olarak sunulmuş ve seçilmiş bildiriler arasında yer almıştır. Organizasyon komitesine teşekkür ederim. Bu bildiri metni genişletilerek El-Cezeri Fen ve Mühendislik Dergisinde yayın sürecine tabi tutularak yayınlanmıştır.

\section{Kaynaklar}

[1]. Kunt, M.A., "Tümüyle Elektrikli Binek Tipli Bir Aracın Advisor Tabanlı Modellenmesi Ve Aerodinamik Direnç Değişiminin Batarya Performansına Etkisi Üzerine Bir Çalışma", ISASTECH 2019, 5-6 Eylül 2019, Ankara, Türkiye.

[2]. Huang Q., Li J., Chen Y., Control of Electric Vehicle. Urban Transport and Hybrid Vehicles, InTech, Chengdu. 2010. 
[3]. Yuan X., Li L., Gou H. and Dong T. "Energy and environmental impact of battery electric vehicle range in China", Applied Energy, 2015, 157: 75-84.

[4]. SAE Standartları Testleri. https://www.eurolab.com.tr/sektorel-test-ve-analizler/endustriyeltestler/sae-standartlari-testleri. 19.09.2019.

[5]. Tat, M.A., Özenç, F., "Otomobil lastiklerinde yuvarlanma direncini etkileyen faktörlerin ve standart yuvarlanma direnci ölçüm tekniklerinin incelenmesi”, Mühendis ve Makine, 2007, 48(572): 16-72.

[6]. Guzzela L., Sciarretta A., Vehicle Propulsion Systems, Springer, Second Edition, USA, 2007.

[7]. Kunt M.A., "Advisor based modelling of the effect of rolling resistance on regenerative braking in all-electric passenger cars", El-Cezerî Journal of Science and Engineering, 2019, 6(3): 847-855.

[8]. Nokian Tyres plc, Finland, European Tyre School Project. Supported by Leonardo da Vinci Programme of European Commision. www.tut.fi/plastics/tyreschool/index.html.

[9]. Trb special report 286 - tires and passenger vehicle fuel economy. Transp ResBoard 2006.

[10]. Sorrentino M., Rizzo G., Sorrentino L., "A study aimed at assessing the potential impact of vehicle electrification on grid infrastructure and road-traffic green house emissions", Applied Energy, 2014, 120: 31-40.

[11]. Millo F., Rolando L., Fuso R., Mallamo F., "Real CO2 emissions benefits and end user's operating costs of a plug-in hybrid electric vehicle", Applied Energy, 2014, 114: 563-71.

[12]. Husain I., Islam M.S. Design, modeling and simulation of an electric vehicle system, $S A E$, SAE Technical Paper No. 1999-01-1149, 1999.

[13]. Markel T., Brooker A., Hendricks T., Johnson V., Kelly K., Kramer B., et al., “ADVISOR: a systems analysis tool for advanced vehicle modelling”, Journal of Power Sources, 2002, 110: 255-66.

[14]. Xu J.W., Zheng L., Simulation and analysis of series hybrid electric vehicle (SHEV) based on ADVISOR, International Conference on Measuring Technology and Mechatronics Automation, Changsha City, China, 13-14 March 2010, 1312-1321.

[15]. Kaloko B.S., Soebagio M.H.P., Purnomo M.H., "Design and development of small electric vehicle using MATLAB/Simulink", International Journal of Computer Applications, 2011, 24: 19-23.

[16]. Schaltz E., "Electrical Vehicle Design and Modeling", Electric Vehicles - Modelling and Simulation, InTech, Shanghai, 2011.

[17]. Mapelli F.L., Tarsitano D., "Modeling of Full Electric And Hybrid Electric Vehicles", New Generation of Electric Vehicles, INTECH Open Access Publisher, 2012.

[18]. Rashid M.I.M., Danial H., "ADVISOR simulation and performance test of split plug-in hybrid electric vehicle conversion”, Energy Procedia, 2017, 105: 1408-1413.

[19]. Suvak H., Erşan K., "The simulation of a full electric vehicle using the city cycle", International Journal of Automotive Engineering and Technologies, 2016, 5(2): 38-46.

[20]. Brooker A., Haraldsson K., Hendricks T., Johnson V., Kelly K., Kramer B., Markel T., O'Keefe M., Sprik S., Wipke K., Zolot M., ADVISOR Documentation, National Renewable Energy Laboratory (NREL), April 2002.

[21]. Wipke K. B., Cuddy M. R., Burch S., "ADVISOR 2.1: A User-friendly advanced power train simulation using a combined backward/forward approach", IEEE Transactions on Vehicular Technology, 1999, 48(6): 1751-1761. 